\title{
TESE
}

\section{Ectasia da Artéria Basilar e Acidente Vascular Cerebral. Estudo de 21 Casos*}

\author{
Roberto de Magalhães Cameiro de Oliveira
}

A ectasia da artéria basilar (EB) é a dilatação do calibre em toda ou parte de sua extensão, e/ou quando for anormalmente tortuosa em seu trajeto. Associa-se freqüentemente ao seu alongamento. É entidade clínica e patológica rara. Pode estar presente desde o nascimento, sendo assintomática. As manifestaçōes clínicas são decorrentes de compressão de nervos cranianos, fenômeno isquêmico ou hemorrágico, síndrome de pseudo-tumor ou hidrocefalia. Procuramos descrever casos da associação de EB e AVC, analisar sua freqüencia, aspectos clínicos e radiológicos, e os mecanismos envolvidos nas diferentes formas de apresentação clínica desta entidade. Encontramos entre 3.250 pacientes com história de doença cerebrovascular, $21 \mathrm{com}$ AVC e EB. A associação de EB e AVC foi prevalente em indivíduos do sexo masculino após 50 anos. Os principais sintomas observados foram hemiparesia, alteração de nervos cranianos e ataxia cerebelar. $\mathrm{Na}$ instalação do AVC foram importantes as tonturas rotatórias e a cefaléia. Os infartos relacionados à EB puderam ser atribuídos a diferentes mecanismos: trombose de artéria, embolia artério-arterial, efeito de massa com angulação e obstrução de ramos das artérias vertebrais e basilar. A ressonância magnética mostrou-se o exame de diagnóstico por imagem mais completo para avaliação das relações entre a EB e as estruturas adjacentes.

- Resumo da Tese de Mestrado aprovada no Curso de Pós-Graduaçăo de Neurologia da Escola Paulista de Medicina. 